\section{ROTHSCHILD COLLECTION OF FLEAS}

An Illustrated Catalogue of the Rothschild Collection of Fleas (Siphonaptera) in the British Museum (Natural History)

By G. H. E. Hopkins and Miriam Rothschild. Vol. 3: Hystrichopsyllidae (Acedestiinae, Anomiopsyllinae, Hystrichopsyllinae, Neopsyllinae, Rhadinopsyllinae, Stenoponiinae). Pp. viii $+560+10$ plates. (London: British Museum (Natural History), 1962.) $168 s$.

I IKE its predecessors, this volume is essentially 1 monographic in nature, since the authors have made every effort to include all relevant information which could be obtained about six of the subfamilies of Hystrichopsyllidae in order amply to meet the stated criterion of facilitating the rapid identification of fleas. Inasmuch as the Rothschild Collection contains 1,478 of the known 1,740 species and sub-species of fleas, and includes type-specimens of 826 forms, even strict adherence to the title of the volume would have been of inestimable value to scientists in this field. However, in Volume 3 alone, Hopkins and Rothschild discuss and illustrate 42 forms not represented in the collection, largely species little known heretofore to scientists of the Western World.

There are approximately 350 names of species or sub-species discussed (of which 73 are cited as synonyms or misidentifications), accompanied by 1,049 figures, of which 308 were especially prepared by Arthur Smith and F. G. A. M. Smit for this volume. There are 34 particularly useful illustrations depicting the skeletal anatomy of fleas, not restricted to the Hystrichopsyllidae, and these include details of the male and female genitalia which have been inadequately used in the past studies on Siphonaptera. There are ten plates of photographs of representative genera and species, illustrating the general configurations of these fleas. The glossary supplements the terms used in Volumes 1 and 3 , and will do much to standardize the terminology used by siphonapterologists, an end that will be furthered by the table which synonymizes and compares the terms used by Hopkins and Rothschild with those recontly proposed by Peus. The family, sub-family and tribal names and references for the fleas considered in Volumes 1 and 2 are presented in this book now that the question of priority for family group names for insects has been settled.

There are terse, dichotomous keys to all the superfamilies and families of fleas, and similar but illus. trated keys to the sub-families, genera, sub-genera, species and sub-species of fleas. Under each name there is a citation of all pertinent references of a taxonomic nature. The text consists of diagnoses and short descriptions designed to include characters sufficient to categorize the species or sub-species and pared of extraneous details. The discussions of the various species are followed by detailed data on material represented in the Rothschild Collection, including careful acknowledgment of the source of specimens donated to the Collection.

The figures are all clear, and well illustrate the pertinent morphological features used in modern systematics. The keys are simple, accurate and easy to use, especially since so many of the critical characters are illustrated. The diagnoses and descriptions are lucid, and deal with well-chosen anatomical structures. The list of records contribute much data of value regarding distribution and even affinities of both the fleas and their hosts.

The system of classification used, based on that of Karl Jordan, but modified, especially concerning taxa and little-known forms, is fully accepted by modern siphonapterologists. The logic and soundness of this scheme of systematics are demonstrated by the relative ease by which unidentified fleas can be determined when using any of the volumes in this series. This facility in accurate identification, and in correctly and promptly learning the affinities of specimens, is also an indication of the scientific and intrinsic value of the book, as well as a tribute to the authors' ability to transfer a thorough knowledge of their subject to the printed page in assimilable form.

Despite the complexity of the subject, the technicality of the terms and multiplicity of references and citations, no errors have been noted by me. The high standards of preparation and editing utilized throughout are illustrated by the fact that the corrigenda for the previous volumes, although based on comments from critical specialists, consist mainly of errors in geographical names due to misspelled labels, clarification about the names used for localities and hosts, and changes in status.

The series of volumes by Hopkins and Rothschild constitute the definitive works on Siphonaptera, and Volume 3 is a fit companion to its predecessors in being completely authoritative and indispensable to anyone whose duties or interests in preventive medicine, mammalogy or entomology entail the identification of fleas or information about their affinities, host-range and geographical distribution.

Publication of the next volume in the series is awaited with keen anticipation. ROBERT TRAUB

\section{ORGANIC CHEMICAL METHODS}

\section{Methoden der Organischen Chemie}

Von J. Houben und Th. Weyl. Vierte, völlig neu gestaltete auflage. Herausgegeben von Eugen Müller. Unter besonderer mitwirkung von $O$. Bayer, H. Meerwein und K. Ziegler. Band 14, Teil 1: Makromolekulare Stoffe. Pp. lxiv +1360 . (Stuttgart: Georg Thieme Verlag, 1961.) 287 D.M.

RGANIC chemists sometimes tend to regard synthetic macromolecules as dull, structurally indefinite species, and essentially the concern of their physico-chemical or industrial colleagues. The editors of the fourth edition of the Houben-Weyl encyclopædia of organic chemical methods have challenged this view in deciding to devote two massive Volumes to the subject. Part 1 deals with the polyzation of vinyl and divinyl compounds, while its companion, when available, will provide a similar treatment of polycondensation and of polymerizations resulting from ring-opening in heterocyclic molecules, such as epoxides.

Librarians of teaching and research institutes who have purchased other, indispensable volumes of the Houben-Weyl series should have no hesitation in adding this one to their shelves. It appears opportunely, when four decades of development of the science and art of polymerization can be surveyed, when naturally occurring polymers have a central place in biochemical thought, and when chemists in general find themselves increasingly concerned with macromolecular structures. The book will have most direct interest, however, to those engaged in 